\title{
Acceptance of genetically modified foods: the relation between technology and evaluation.
}

Citation for published version (APA):

Tenbült, P., de Vries, N. K., van Breukelen, G., Dreezens, E., \& Martijn, C. (2008). Acceptance of genetically modified foods: the relation between technology and evaluation. Appetite, 51(1), 129-136. https://doi.org/10.1016/j.appet.2008.01.004

Document status and date:

Published: 01/01/2008

DOI:

10.1016/j.appet.2008.01.004

Document Version:

Publisher's PDF, also known as Version of record

Document license:

Taverne

Please check the document version of this publication:

- A submitted manuscript is the version of the article upon submission and before peer-review. There can be important differences between the submitted version and the official published version of record.

People interested in the research are advised to contact the author for the final version of the publication, or visit the DOI to the publisher's website.

- The final author version and the galley proof are versions of the publication after peer review.

- The final published version features the final layout of the paper including the volume, issue and page numbers.

Link to publication

\footnotetext{
General rights rights.

- You may freely distribute the URL identifying the publication in the public portal. please follow below link for the End User Agreement:

www.umlib.nl/taverne-license

Take down policy

If you believe that this document breaches copyright please contact us at:

repository@maastrichtuniversity.nl

providing details and we will investigate your claim.
}

Copyright and moral rights for the publications made accessible in the public portal are retained by the authors and/or other copyright owners and it is a condition of accessing publications that users recognise and abide by the legal requirements associated with these

- Users may download and print one copy of any publication from the public portal for the purpose of private study or research.

- You may not further distribute the material or use it for any profit-making activity or commercial gain

If the publication is distributed under the terms of Article $25 \mathrm{fa}$ of the Dutch Copyright Act, indicated by the "Taverne" license above, 


\title{
Acceptance of genetically modified foods: The relation between technology and evaluation
}

\author{
Petra Tenbült ${ }^{\mathrm{a}, *}$, Nanne K. De Vries ${ }^{\mathrm{a}}$, Gerard van Breukelen ${ }^{\mathrm{b}}$, \\ Ellen Dreezens ${ }^{\mathrm{c}}$, Carolien Martijn ${ }^{\mathrm{c}}$ \\ ${ }^{a}$ Department of Health Education and Promotion, Universiteit Maastricht, The Netherlands \\ ${ }^{\mathrm{b}}$ Department of Methodology and Statistics, Universiteit Maastricht, The Netherlands \\ ${ }^{\mathrm{c}}$ Department of Clinical Psychological Science, Universiteit Maastricht, The Netherlands \\ Received 9 August 2007; received in revised form 13 January 2008; accepted 17 January 2008
}

\begin{abstract}
This study investigates why consumers accept different genetically modified food products to different extents. The study shows that whether food products are genetically modified or not and whether they are processed or not are the two important features that affect the acceptance of food products and their evaluation (in terms of perceived healthiness, naturalness, necessity and tastiness). The extent to which these evaluation attributes and acceptance of a product are affected by genetic modification or processing depends on whether the product is negatively affected by the other technology: Any technological change to a 'natural' product (when nonprocessed products are genetically modified or when nongenetically modified products are processed) affect evaluation and acceptance stronger than a change to an technologically adapted product (when processed products are also genetically modified or vice versa).

Furthermore, evaluation attributes appear to mediate the effects of genetic modification and processing on acceptance.

(C) 2008 Elsevier Ltd. All rights reserved.
\end{abstract}

Keywords: Food innovations; Genetic modification; Technology; Processing

\section{Introduction}

Acceptance of new food technologies, especially of genetically modified (GM) foods, has recently attracted much attention in research. It has been related to trust and confidence in science, government and biotechnology companies and to socio-demographic factors (Hossain, Onyango, Adelaja, Schilling, \& Hallman, 2002; Onyango \& Nayga, 2004), to information provided about GM (Grunert, Bredahl, \& Scholderer, 2003) and to the nature of the GM technology that has been used (Burton \& Pearse, 2003; Frewer, Howard, \& Shepherd, 1998). These studies provide insight into personal differences between consumers related to the acceptance of GM and whether information about the applied technology influences this acceptance. But these investigations do not show whether and how acceptance of GM foods relates to specific features of products. Does the nature of a genetically

\footnotetext{
* Corresponding author.

E-mail address: p.m.a.tenbult@uvt.nl (P. Tenbült).
}

modified product influence its evaluation? And if so, why are some GM products less or more likely to be accepted?

People's acceptance of GM foods has been shown to depend on their general attitudes towards genetic engineering (Frewer et al., 1998). Many studies (Bredahl, 2001; Gamble, Muggleston, Hedderley, Parminter, \& Vaughan, 2000; Grunert et al., 2003; Saba \& Vassallo, 2002; Tenbült, De Vries, Dreezens, \& Martijn, in press) showed that the general attitude towards the application of GM in food production is negative. Therefore, GM products are in general less well accepted than their conventional counterparts.

But general attitudes are not the sole predictors of people's attitude towards GM. Some studies (Frewer, Howard, \& Shepherd, 1996; Tenbült, De Vries, Dreezens, \& Martijn, 2005) provide evidence that although people have a general negative attitude towards GM, evaluations are product specific and not unconditionally associated with the technology overall. For example, some consumers find GM more acceptable when it involves plants, compared to when it involves animals (Frewer et al., 1996). Others find genetic modification more acceptable when it is used to reduce the use of pesticides than when it is used to reduce prices (Pew Initiative, 2003). 
Gamble et al. (2000) suggest that the effect of genetic modification differs between product categories because genetic modification is a feature that affects the evaluation of products. The authors showed that the production technology (GM) is more important for consumers' evaluation of products when it concerns apples than when it concerns chocolate biscuits. The authors suggested that because chocolate biscuits are already seen as unhealthy, consumers are indifferent to whether the production technology adds to this unhealthiness.

A study of Tenbült, De Vries, Dreezens, and Martijn (2007) showed that whether food products are processed or appear in their natural form is an important factor in determining the acceptance of GM products. This may suggest that processing of products, in addition to genetic modification, is an important feature that affects consumers' evaluation of products and consequently their acceptance. To illustrate this with an example from Gamble et al. (2000), apples are nonprocessed products (have their natural form) and chocolate biscuits are manufactured and therefore processed products. The evaluation of chocolate biscuits is (already) negatively affected by processing. Therefore, the production technology (GM) affects the evaluation of a processed product (chocolate biscuits) less than when the product was not previously processed (apples). If indeed evaluation differences are related to processing, the same differences should appear when nonprocessed products (apples) are compared to their processed forms (i.e. apple juice).

The aim of the present study is to examine how genetic modification affects the evaluation and acceptance of processed and nonprocessed food products. We hypothesize that GM and processing are both features that affect the acceptance of products. We also hypothesize that the extent to which the acceptance of a product is affected by GM or processing depends on whether it is already negatively affected by the other feature: the acceptance of GM foods will be less sensitive to processing effects than the acceptance of non-GM food and the acceptance of processed food products will be less affected by GM than the acceptance of nonprocessed food.

In the study of Gamble et al. (2000) perceived healthiness is measured as a decisive factor in product evaluation. In other studies evaluations of other product attributes like perceived naturalness (Frewer et al., 1996; Rozin et al., 2004; Tenbült et al., 2005), perceived tastiness (MAPP annual report, 2000) and perceived necessity (Tenbült et al., 2005) were used to explain why GM products are less well accepted than their conventional counterparts. We hypothesize that the extent to which these evaluations of product attributes (perceived naturalness, healthiness, necessity and tastiness) are affected by GM or processing depends on whether the product is negatively affected by another feature. Hence, the evaluation of product attributes of GM food will be relatively insensitive to processing effects and the evaluation of product attributes of processed food products are relatively unaffected by GM. Moreover, we will investigate to what extent these product attribute evaluations mediate the effects of GM and processing on product acceptance, under the assumption that these attributes affect product acceptance rather than just being correlated with acceptance.

\section{Methods}

\section{Pilot study}

In a pilot-study with 36 undergraduate students ( 21 women, 15 men) of Universiteit Maastricht with a mean age of 20.23 years (S.D. $=2.04$, range $18-30$ ) we investigated the extent to which genetic modification and processing affect acceptance. We used three food products that have well-known processed forms and nonprocessed forms. The selected products were potato (with crisps as processed form), tomato (with ketchup as processed form) and chicken meat (with chicken fingers as processed form). In total, participants had to respond towards twelve products, three conventional nonprocessed products (tomato, potato and chicken), three conventional processed products (ketchup, crisps and chicken fingers), three GM nonprocessed products (GM tomato, GM potato and GM chicken) and three GM processed products (GM ketchup, GM crisps and GM chicken fingers). Seven questions were asked for each of the twelve products. Four of these measured the extent to which the products were seen as "natural", "necessary", "healthy" and "tasteful". Three questions were used to measure to what extent the genetically modified variant of that certain product would be accepted ('I will eat this (product)', 'I accept this (product)', 'I trust this (product)'). These three questions were averaged into one acceptance score per person per condition, which had a satisfactory internal consistency (alpha $>0.76$ in each condition).

Because all five dependent variables (attributes and acceptance) were measured on the same 5-point scale and thereby commensurate, a 2 (technology: GM versus non$\mathrm{GM}) \times 2$ (processing: processed versus nonprocessed products) $\times 5$ (outcome: acceptance, naturalness, healthiness, necessity, tastiness) within-subject ANOVA was run. Highly significant $(p<0.001)$ interactions were found of technology, processing and technology $\times$ processing with outcome, implying that experimental effects varied between dependent variables. Therefore, a 2 (technology) $\times 2$ (processing) within-subject ANOVA was run per dependent variable. These five two-way within-subject ANOVAs showed main effects for technology (all $p$ 's $<0.001$ ), main effects for processing (all $p$ 's $<0.001$, except for tastiness, n.s.) and significant interaction effects (all $p$ 's $<0.001$, except for tastiness, n.s.). The results showed that GM products are less well accepted and are perceived as less natural, healthy, necessary and tasty than conventional products. Likewise, processed products are less well accepted and are perceived as less natural, healthy and necessary than nonprocessed products. Besides this, the interaction effects showed that the effect of GM on a products' acceptance, perceived naturalness, healthiness or necessity is smaller for processed food than for nonprocessed food. Likewise, the effect of processing on a products' acceptance, perceived naturalness, healthiness or necessity is smaller for GM than for non-GM food. Although the pilot study showed that GM and processing both affect the evaluation and the acceptance of foods, the interaction effect might perhaps be the result of a floor effect: the processed non-GM products in this 
study were perceived as not natural, not healthy and not necessary for people's diet (all means below the midpoint of the 5-point Likert scale). This might have reduced the maximum attainable GM effect for processed products. Based on these results and to exclude the possibility of a floor effect we decided to use food products in our main study that have both a nonprocessed and a processed form that is perceived as healthy and natural.

\section{Sample}

One hundred and three consumers (63 women, 31 men and 9 who did not report their gender) participated in this study. The mean age of the participants was 39.75 years (S.D. $=13.52$, range 18-69). Participants responded to an advertisement in a local newspaper, which asked for people to participate in a study about food preferences in return for a small payment. The participants completed the experiment on an individual basis.

\section{Design}

We used a $2 \times 2$ within-subjects design, with GM yes/no and processing yes/no as within-subject factors, acceptance as outcome variable and perceived naturalness, healthiness, necessity and tastiness as possible moderators and mediators.

\section{Materials}

\section{Food products}

We selected two food products that have a natural, wellknown processed form in addition to their nonprocessed form. The selected products were an apple (with apple juice as processed form) and an orange (with orange juice as processed form). We suggest that apple juice and orange juice are both perceived in general as natural, healthy products although they are processed. These four products were presented in a non-GM and a genetically modified form. In total, participants had to respond towards eight products, two conventional nonprocessed products (e.g. apple and orange), two conventional processed products (apple juice and orange juice), two GM nonprocessed products (GM apple and GM orange) and two GM processed products (GM apple juice and GM orange juice). First seven questions were asked about each of the four nonGM products, with the products presented in a random order; subsequently, the four GM products were presented in random order and rated on each of the seven scales.

\section{Questionnaire}

Seven questions were asked for each of the eight products. Four of them measured the extent to which the products were seen as "natural", "necessary", "healthy" and "tasteful" ('I believe this (product) is natural', 'I believe this product is healthy', 'I believe this (product) is healthy', 'I believe this (product) is tasteful'). We will refer to these four questions as evaluation attributes. The remaining three questions were used to measure to what extent the genetically modified variant of that certain product would be accepted ('I will eat this (product)', 'I accept this (product)', 'I trust this (product)'). To make a clear distinction, the non-GM products will be referred to as conventional products. The genetically modified variants of the conventional products will be referred to as GM products.

The three questions about acceptance ('I will eat this (product)', 'I accept this (product)', 'I trust this (product)') had satisfactory internal consistency (alpha $>0.71$ in each condition). Therefore, these three questions were reduced to one acceptance measure by calculating the mean of these three questions for each of the eight products. Subsequently, the means of the two conventional nonprocessed products (i.e. apple and orange) were calculated per outcome (perceived naturalness, healthiness, necessity, tastiness and acceptance), and likewise for the two GM nonprocessed products, the two GM nonprocessed products, and the two GM processed products, giving one measure per person per condition per dependent variable. Factor and reliability analyses of these five dependent variables were conducted for each experimental condition separately and showed these variables to be highly correlated, suggesting reduction of variables into one overall acceptance or attitude outcome variable. On the other hand, ANOVA showed experimental effects to vary between the five dependent variables, justifying an ANOVA per dependent variable (for details see the Results section).

\section{Procedure}

The experimenter welcomed the participants and they were told that the experiment consisted of the completion of one 10 min questionnaire. The participants signed an informed consent form and were seated in a research cubicle containing only a computer on a desk and a chair. The instructions were presented on the computer screen. The instructions informed the participants that the questionnaire consisted of two parts and that they had to answer seven questions about four conventional food products by pressing a 1 (I totally do not agree), 2 (I do not really agree), 3 (I do not know), 4 (I agree a bit) or a 5 (I totally agree). Then, the participants were asked to imagine one of the four products (the order was determined at random for each participant) for a moment after which the seven questions (in random order) were answered. The questions were presented in the centre of the screen and appeared after a red fixation cross which was visible for 1000 ms. Answering alternatives were shown on the screen. The question remained on the screen until the participants responded. When the first part of the questionnaire was completed, another instruction on the screen informed the participants that in the second part they would have to do the same as in the first part, but with the difference that they now had to imagine the same products in a genetically modified form. At the end of the questionnaire, the participants were thanked.

\section{Results}

We are interested in the relation between acceptance of food products and the extent to which genetic modification and 
Table 1

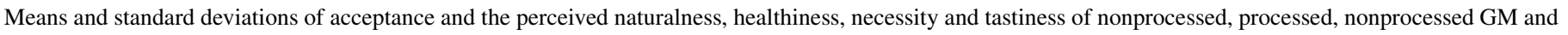
processed GM products

\begin{tabular}{|c|c|c|c|c|c|c|c|c|c|c|}
\hline & \multicolumn{2}{|c|}{ Acceptance } & \multicolumn{2}{|c|}{ Naturalness } & \multicolumn{2}{|c|}{ Healthiness } & \multicolumn{2}{|c|}{ Necessity } & \multicolumn{2}{|c|}{ Tastiness } \\
\hline & $M$ & S.D. & $M$ & S.D. & $M$ & S.D. & $M$ & S.D. & $M$ & S.D. \\
\hline \multicolumn{11}{|l|}{ Non-GM } \\
\hline Nonprocessed & 4.26 & 0.80 & 4.44 & 0.76 & 4.57 & 0.72 & 4.07 & 0.96 & 4.30 & 0.80 \\
\hline Processed & 3.49 & 1.03 & 3.43 & 1.02 & 3.67 & 1.01 & 2.91 & 1.12 & 3.87 & 1.13 \\
\hline \multicolumn{11}{|l|}{ GM } \\
\hline Nonprocessed & 2.14 & 1.19 & 1.90 & 1.10 & 2.35 & 1.28 & 1.89 & 1.09 & 2.61 & 1.24 \\
\hline Processed & 2.37 & 1.05 & 1.84 & 1.02 & 2.20 & 1.23 & 1.81 & 0.99 & 2.52 & 1.20 \\
\hline
\end{tabular}

Note: All simple effects were significant $(p<0.05)$ except for tastiness (GM nonprocessed versus GM processed).

processing affect acceptance. We hypothesize that GM and processing both affect the acceptance and the evaluation (perceived healthiness, naturalness, necessity and tastiness) of products. We also hypothesize that the extent to which GM or processing affects the acceptance and evaluation of a product depends on whether it is already negatively affected by the other feature. In other words, we predict interaction between both experimental factors (GM and processing) with respect to the outcome (acceptance) and the possible moderators and mediators (perceived naturalness, healthiness, necessity and tastiness).

\section{Processing versus technology}

First, checking for a possible floor effect in view of results in the pilot study, we examined whether the selected conventional processed food products were perceived as natural and healthy. As Table 1 shows, the perceived naturalness and perceived healthiness of the conventional processed products are both above the midpoint of the 5-point Likert scale.

Because all five dependent variables (the evaluation attributes) were measured on the same 5-point scale and thereby commensurate, we used a 2 (technology: GM versus non-GM) $\times 2$ (processing: processed versus nonprocessed products) $\times 5$ (outcome: acceptance, naturalness, healthiness, necessity, tastiness) within-subject ANOVA to test whether experimental effects varied between dependent variables or not. We found highly significant $(p<0.001)$ interactions of technology, processing and technology $\times$ processing with outcome, implying that experimental effects varied between dependent variables. Although a scale and a factor analysis suggested that the five evaluation attributes might be treated as different indicators of a common underlying construct (acceptance), this significant interaction effect of the threeway ANOVA indicates that it is plausible that interaction between technology and processing differs between evaluation attributes. Therefore, we next ran a 2 (technology) $\times 2$ (proces(processing) within-subject ANOVA per dependent variable, starting with the primary outcome, acceptance. This analysis showed a main effect for technology and a main effect for processing (see Table 2). Participants appeared to accept conventional products more than GM products and to accept nonprocessed products more than processed products (for means see Table 1). The interaction between technology and processing was also significant (see Table 2), implying that the main effects of GM and processing are averages of so-called simple effects and that these simple effects must be tested. Testing simple effects, that is, effects of GM for nonprocessed and for processed food separately, showed that the difference in acceptance of conventional and GM products is greater when it concerned nonprocessed products than when it concerned processed products. Likewise, simple effects tests showed that the difference in acceptance between nonprocessed and processed products is greater when it concerned conventional products than when it concerned GM products (for means see Table 1). This suggests that the extent to which GM or processing affect the acceptance of a product depends on whether it is negatively affected by the other feature.

We used the same $2 \times 2$ within-subject ANOVA to test for the effects of technology and processing on each evaluation attribute (perceived naturalness, healthiness, necessity and tastiness). The analyses showed a main effect of technology and a main effect of processing for acceptance, perceived naturalness, perceived healthiness, perceived necessity and

Table 2

Main and interaction effects of technology and processing on acceptance, perceived naturalness, perceived healthiness, perceived necessity and perceived taste $(N=103)$

\begin{tabular}{|c|c|c|c|c|c|}
\hline & Acceptance, $F$ & Naturalness, $F$ & Healthiness, $F$ & Necessity, $F$ & Tastiness, $F$ \\
\hline Technology $(\mathrm{T})$ & $231^{* * *}$ & $318^{* * *}$ & $239^{* * *}$ & $232^{* * *}$ & $156^{* * *}$ \\
\hline Processing $(\mathrm{P})$ & $13^{*}$ & $60^{* *}$ & $53^{* *}$ & $74^{* *}$ & $12^{*}$ \\
\hline $\mathrm{T} \times \mathrm{P}$ & $102^{* * *}$ & $91^{* *}$ & $57^{* *}$ & $70^{* * *}$ & $12^{*}$ \\
\hline
\end{tabular}

Note: d.f. $=1,102$.

${ }^{*} p<0.01$.

** $p<0.001$. 
Table 3

Total effect $(=$ simple effect of technology or processing on acceptance $)=$ direct effect + mediated effect $($ mediated effect $=$ technology or processing effect on the mediator (simple effects) ${ }^{*}$ mediator effect on acceptance)

\begin{tabular}{|c|c|c|c|c|c|}
\hline Predicted effect & & $\begin{array}{l}\text { Technology effect, } \\
\text { nonprocessed products }\end{array}$ & $\begin{array}{l}\text { Technology effect, } \\
\text { processed products }\end{array}$ & $\begin{array}{l}\text { Processing effect, } \\
\text { non-GM products }\end{array}$ & $\begin{array}{l}\text { Processing effect, } \\
\text { GM products }\end{array}$ \\
\hline Simple effects & $\begin{array}{l}\text { Naturalness } \\
\text { Healthiness } \\
\text { Necessity } \\
\text { Tastiness }\end{array}$ & $\begin{array}{l}-2.55^{\text {***** }} \\
-2.22^{\text {***** }} \\
-2.18^{\text {**** }} \\
-1.69^{\text {**** }}\end{array}$ & $\begin{array}{l}-1.59^{\text {**** }} \\
-1.47^{\text {**** }} \\
-1.10^{\text {*** }} \\
-1.35^{\text {*** }}\end{array}$ & $\begin{array}{l}-1.01^{\text {**** }} \\
-0.90^{\text {**** }} \\
-1.17^{\text {**** }} \\
-0.43^{\text {**** }}\end{array}$ & $\begin{array}{l}-0.05 \\
-0.15^{*} \\
-0.08 \\
-0.08\end{array}$ \\
\hline $\begin{array}{l}\text { Mediator effects } \\
\text { on acceptance }\end{array}$ & $\begin{array}{l}\text { Naturalness } \\
\text { Healthiness } \\
\text { Necessity } \\
\text { Tastiness } \\
\text { Adjusted } R^{2}\end{array}$ & $\begin{array}{l}0.22^{*} \\
0.24^{\text {*** }} \\
0.34^{\text {*** }} \\
0.25^{\text {*** }} \\
0.67\end{array}$ & $\begin{array}{l}0.19^{* * *} \\
0.14 \\
0.23^{* * *} \\
0.23^{* * *} \\
0.65\end{array}$ & $\begin{array}{l}0.11 \\
0.17^{*} \\
0.22^{* * *} \\
0.31^{\text {*** }} \\
0.71\end{array}$ & $\begin{array}{l}0.18 \\
0.25^{* *} \\
0.21^{*} \\
0.39^{* * *} \\
0.55\end{array}$ \\
\hline Direct effect & & 0.13 & -0.06 & -0.12 & $-0.13^{* * *}$ \\
\hline Total effect & & $-2.12^{* * *}$ & $-1.13^{* * *}$ & $-0.77^{* * * *}$ & $-0.23^{* * *}$ \\
\hline
\end{tabular}

${ }^{*} p<0.05$.
${ }^{* * *} p<0.01$.
${ }^{* * * *} p<0.001$.

perceived tastefulness (see Table 2). Participants appeared to accept conventional products and nonprocessed products more and perceive them as more natural, healthy, necessary and tasty than GM and processed products, respectively (for means see Table 1). The interaction between technology and processing was also significant, implying that the main effects are averages of simple effects. Testing simple effects showed that the differences in acceptance, perceived naturalness, healthiness, necessity and tastiness of conventional and GM products were greater for nonprocessed products than for processed products. Also, the effect of processing was smaller for GM than for nonGM products (for means see Table 1). GM and processing both affected the evaluation and acceptance of foods in a nonadditive way as there was again interaction. The acceptance and evaluation of a product were affected by GM more strongly for nonprocessed than for processed products and the acceptance and evaluation were affected by processing more strongly for non-GM than for GM products.

\section{Moderation and mediation}

As mentioned in the introduction, evaluations of different product attributes (perceived healthiness, naturalness, necessity and tastiness) are used to explain why GM products are less well accepted than their conventional counterparts. We aimed to investigate whether these product attribute evaluations moderate or mediate the relation between GM and product acceptance and the relation between processing and product acceptance.

First we will explain the three conditions that must be satisfied for mediation to occur, followed by how to measure moderation and mediation in a within subjects design.

Following Baron and Kenny (1986), mediation implies that (1) the experimental factor affects the outcome "product acceptance" and (2) the experimental factor affects the mediator and (3) the mediator affects the outcome, adjusted for the experimental factor. Two remarks about this procedure must be made, however. First, as MacKinnon, Lockwood, Hoffman, West, and Sheets (2002) showed, the test of criterion (1) has low power if there is complete mediation, because the total experimental effect on the outcome is then the product of the two effects on which criteria (2) and (3) are based. Second, our design allows us to test whether the assumed mediators predict product acceptance, but not whether they causally affect acceptance. Mediation was tested following the method of Judd, Kenny and McClelland (2001), of which the technical details are given in Appendix A to this paper since our withinsubjects design requires a somewhat different approach. This method also allows a prior test of moderation of experimental effects by the assumed mediator.

Because of the interaction effect of processing and technology on acceptance (see Table 2), we investigated mediation of the effect of technology on acceptance separately for processed and nonprocessed products, and mediation of the effect of processing on acceptance separately for GM and nonGM products. So the Baron and Kenny (1986) procedure as adapted to within-subject designs by Judd et al. (2001) was carried out four times in total. Results are shown in Table 3.

\section{Moderation}

To test whether the four evaluation attributes (perceived naturalness, healthiness, necessity and tastiness) moderate the effects of GM (yes/no) and processing (yes/no) on acceptance we applied the model in Eq. (A.5) (see Appendix A) four times (technology effect on acceptance of nonprocessed products, technology effect on acceptance of processed products, processing effect on acceptance of non-GM products and processing effect on acceptance of GM). Each time all four potential moderators were included (perceived naturalness, healthiness, necessity and tastiness) following model (A.5).

We found no significant moderation of an experimental effect by any of the four mediators in any of the four analyses (GM effect for nonprocessed products, GM effect for processed products, processing effect for non-GM products and proces- 
sing effect for GM products), all $p>0.05$. Mediation was therefore evaluated using Eq. (A.7) in Appendix A.

\section{Mediation}

To test whether the four evaluation attributes (perceived naturalness, healthiness, necessity and tastiness) mediate the effects of GM (yes/no) and processing (yes/no) on acceptance we applied the model in Eq. (A.7) four times (technology effect for the acceptance of nonprocessed products, technology effect for the acceptance of processed products, processing effect for the acceptance of non-GM products and processing effect for the acceptance of GM products). Each time all four potential mediators were included (perceived naturalness, healthiness, necessity and tastiness).

\section{Total, mediated and direct effects}

Table 3 shows the direct, mediated and total effects of GM for nonprocessed and processed products and the effects of processing for non-GM and GM products. By investigating these effects we can determine whether mediated GM effects depend on whether the product was processed or not and whether mediated processing effects depend on whether the product was genetically modified or not.

\section{Technology effect for nonprocessed products}

We found a significant effect of all four evaluation attributes (M) on acceptance and the direct effect of GM on acceptance was close to zero and not significant (see Eq. (A.7) in Appendix A). This suggests that the four predictive evaluation attributes mediated almost the entire effect (complete mediation) of GM on the acceptance of nonprocessed products (for the direct effect and the effects of the mediators see Table 3 ).

\section{Technology effect for processed products}

We found a significant effect of perceived naturalness, necessity and tastiness on acceptance. The direct effect was not significant and close to zero. This suggests that the three predictive evaluation attributes mediated almost the entire effect (complete mediation) of GM on the acceptance of nonprocessed products (for all effects, see Table 3 ).

\section{Technology effect for nonprocesssed versus processed products}

The difference between total and direct technology effect on acceptance is much larger for nonprocessed than for processed products (see bottom of Table 3). This can be explained by the effect of technology on the mediators, which is greater for unprocessed products compared to processed products (see upper half of Table 3). It can be concluded that the total and mediated effect of technology on acceptance are both larger for nonprocessed than for processed products.

\section{Processing effect for non-GM products}

We found a significant effect of healthiness, necessity and tastiness on acceptance and the direct effect was close to zero and not significant (see Eq. (A.7) in Appendix A). This suggests that these three predictive evaluation attributes mediated almost the entire effect (complete mediation) of processing on the acceptance of non-GM products (for all effects, see Table 3 ).

\section{Processing effect for GM products}

We found a significant effect of perceived healthiness, necessity and tastiness on acceptance. The direct effect was significant. This suggests that the three predictive evaluation attributes partly mediated the effect of processing on the acceptance of GM products. The rest of the mediated effect is due to the direct effect (see Table 3).

\section{Processing effect for non-GM versus GM products}

The difference between total and direct processing effect on acceptance is much larger for non-GM than for GM products (see bottom of Table 3). This can be explained by the effect of processing on the mediators, which is greater for non-GM products compared to GM products (see upper half of Table 3). It can be concluded that the effect of processing on acceptance is more strongly mediated by perceived naturalness, healthiness, necessity and tastiness when it concerns non-GM products than when it concerns GM products.

We found no moderation of effects of technology or processing on acceptance by naturalness, necessity, healthiness or tastiness. We also found that about all the evaluation attributes contribute to mediation of GM effects for nonprocessed and processed products and of processing effects for non-GM and GM products. However, the interpretation of naturalness, healthiness, necessity and tastiness as mediators is tentative because our design does not allow causal inferences between these five variables. Scale and factor analysis suggested that these five dependent variables might also be treated as different indicators of a common underlying construct, such as a general attitude towards the product.

\section{Discussion}

In the study presented, we investigated the extent to which genetic modification and processing affect acceptance. Furthermore we investigated whether the evaluation attributes moderate or mediate GM and processing effects on product acceptance.

This study showed that GM and processing are both factors that affect the evaluation and acceptance of products. The extent to which GM or processing affects the evaluation and acceptance of a product depends on whether the product is negatively affected by the other technology. Besides this, this study showed that this effect is not the result of a floor effect.

The current study also showed that acceptance of 'natural' products is affected by processing or GM as mediated (to a large extent) by the evaluation attributes. In contrast, the acceptance of products that are changed in one technology (either GM or processing) is suggested to be less affected by effects of the other technology, and is less strongly mediated by these evaluation attributes.

We agree with Gamble et al. (2000) that effects of genetic modification differ between product categories because it is a feature that affects the evaluation of products. We do not agree 
with the authors' suggestion that when products (e.g. chocolate biscuits) are already seen as unhealthy, consumers are indifferent to whether the production technology is also regarded as unhealthy. The results of Gamble et al. (2000) can be better explained by taking the processing of products into account, which appears to be an additional feature that affects the evaluation and acceptance of products. Besides this, we showed that when processed products are perceived as healthy, they are still less affected by GM compared to nonprocessed products. A possible explanation is that the evaluation of the chocolate biscuits was already affected by processing, with the result that the used production technology (GM) affected the evaluation of this processed product less compared to when the product was not processed.

A limitation of this study is that our causal model assumed that necessity, naturalness, health and tastiness affect acceptance, but not each other and that acceptance does not affect any of these four attributes. The more complicated model including these interdependencies can itself not be tested with the current data, only the size and significance of the effects it assumes could be tested. Although scale and factor analysis suggested that the five evaluation attributes might also be treated as different indicators of a common underlying construct (acceptance), literature and the significant interaction effect of the three-way ANOVA indicate that it is plausible that interaction between technology and processing differs between evaluation attributes. As mentioned in the introduction, different studies (Frewer et al., 1996; Gamble et al., 2000; MAPP annual report, 2000; Rozin et al., 2004; Tenbült et al., 2005) use different evaluation attributes to explain why GM products are less well accepted than their conventional counterparts. Whether or not different evaluation attributes measure the same underlying construct could be interesting for generalizing results. Future research could therefore focus on whether different evaluation attributes measure the same underlying construct or whether they are conceptually different.

Another limitation is that we only used a small number of products and that the products were always first presented in the non-GM form and subsequently in the GM form. It is possible that this fixed order could have led to a bias, although we did randomize the order of the nonprocessed and processed products. Besides this, we replicated the findings of our pilot study with a different set of products and with non-student consumers.

Future research could also focus on whether other product features affect the evaluation and acceptance of products, for example whether the product is vegetable or animal. Besides this, benefits that are created by new technologies (e.g. health benefits) could also be product features that affect the evaluation and acceptance of products.

The current study showed that product features such as GM and processing lead to less acceptance of a product, which is associated with more negative evaluations of important product attributes such as the perceived healthiness, naturalness, necessity and tastiness. These effects however are not additive, as the effect of GM on acceptance and evaluation is larger for nonprocessed than for processed products and the effect of processing is larger for non-GM than for GM products.

\section{Appendix A}

The mediation model assumes a three-variable system (Baron \& Kenny, 1986). It consists of three causal paths:

1. The direct effect of independent variable on outcome, adjusted for the mediator (path c).

2. The effect of mediator on outcome, adjusted for the independent variable (path b).

3. The effect of independent variable on mediator (path a).

The total effect of the independent variable is the sum of two effects: the direct effect (c) plus the indirect or mediated effect $(\mathrm{a} \times \mathrm{b})$, and is obtained by regressing outcome on independent variable without adjusting for the mediator.

To test for mediation, we need three regression analyses according to Baron and Kenny (1986). First, the mediator has to be regressed on the independent variable (with $\alpha_{1}$ denoting path a of the mediated effect):

$M=\alpha_{0}+\alpha_{1} X$

Secondly, the dependent variable has to be regressed on the independent variable (with $\delta_{1}$ denoting the total effect):

$Y=\delta_{0}+\delta_{1} X$

Third, the dependent variable has to be regressed on both the independent variable and on the mediator, with $\beta_{1}$ denoting the direct effect (path c) and $\beta_{2}$ denoting path $\mathrm{b}$ of the mediated effect:

$Y=\beta_{0}+\beta_{1} X+\beta_{2} M$

The total effect is equal to the direct effect + mediated effect, that is

$\delta_{1}=\beta_{1}+\alpha_{1} \times \beta_{2}$

To conclude that there is mediation, both $\alpha_{1}$ and $\beta_{2}$ must be unequal to zero, in which case the direct effect $\beta_{1}$ is unequal to the total effect $\delta_{1}$ (partial mediation). In case of full mediation, $\beta_{1}$ is equal to zero. Note that models (A.1)-(A.3) are partly within-subject regression models, since $X$ varies within subjects and $Y$ and $M$ vary within and between subjects. This calls for an adaptation of the Baron and Kenny procedure to within-subject designs.

Following the procedure in Judd et al. (2001) for mediation and moderation analysis in within-subjects designs, we tested for mediation and moderation (of technology or processing effects on acceptance by each potential mediator/moderator) by regression of differences in acceptance (between conditions) on differences in mediators (between conditions). The starting point for this is model (A.3) for the regression of acceptance $(Y)$ on GM $(X)$ and mediator $(M)$. Model (A.3) assumes no moderation of the GM effect on acceptance by the mediator $M$. 
To test for moderation, we extended (A.3) as follows:

$Y_{i j}=\beta_{0}+\beta_{1} X_{j}+\beta_{2} M_{i j}+\beta_{3} X_{j} M_{i j}$

where $Y_{i j}$ is acceptance by person $i$ in GM condition $j(j=1$ means $\mathrm{GM}, j=0$ means non-GM) and $X_{j}$ is coded as: $\mathrm{GM}=1$; non-GM $=-1$. In terms of Eq. (A.5), moderation occurs if $\beta_{3}$ is unequal to zero. If $\beta_{3}=0$, then (A.5) reduces to (A.3). To see how this model can be applied to within-subject designs, we need the following steps.

When $X=1(\mathrm{GM})$, the model is

$Y_{i 1}=\left(\beta_{0}+\beta_{1}\right)+\left(\beta_{2}+\beta_{3}\right) M_{i 1}$

When $X=-1$ (non-GM), the model is

$Y_{i 0}=\left(\beta_{0}-\beta_{1}\right)+\left(\beta_{2}-\beta_{3}\right) M_{i 0}$

So the within-subject difference in acceptance between GM and non-GM is

$\Delta Y_{i}=Y_{i 1}-Y_{i 0}$

$\Delta Y_{i}=\left(2 \beta_{1}\right)+\beta_{2}\left(M_{i 1}-M_{i 0}\right)+\beta_{3}\left(M_{i 1}+M_{i 0}\right)$

which shows that:

1. $M$ is a moderator of the GM effect on acceptance if the sum $\left(M_{i 1}+M_{i 0}\right)$ is predictive of the difference in acceptance between GM and non-GM.

2. Assuming absence of moderation (i.e. $\beta_{3}=0$ ), $M$ is a mediator of the GM effect on acceptance if the difference $\left(M_{i 1}-\mathrm{M}_{i 0}\right)$ is predictive of the difference in acceptance between GM and non-GM.

3. Assuming absence of moderation $\left(\beta_{3}=0\right)$ the intercept $2 \beta_{1}$ of the regression in (A.6) is the direct effect of GM versus non-GM on acceptance, see Eq. (A.3).

We therefore regressed the difference in acceptance between GM and non-GM on both the $M$ difference and the $M$ sum (Eq. (A.6)), including into (A.6) all four potential mediators (naturalness, healthiness, necessity, tastiness) at the same time.

Because none of the four attributes significantly moderated the technology effect either for nonprocessed or for processed products and none moderated the processing effect either for GM or for non-GM products, it can be concluded that $\beta_{3}=0$ for each attribute in each of the four simple effects analyses and therefore:

$\Delta Y_{i}=\left(2 \beta_{1}\right)+\beta_{2}\left(M_{i 1}-M_{i 0}\right)$

where $\Delta Y_{i}=$ total effect, $\left(2 \beta_{1}\right)=$ direct effect, and $\beta_{2}$ $\left(M_{\mathrm{i} 1}-M_{\mathrm{i} 0}\right)=$ mediated effect (note that the mean of $M_{1}-M_{0}$ across all subjects estimates $\alpha_{1}$ in Eq. (A.1)).

\section{References}

Baron, R. M., \& Kenny, D. A. (1986). The moderator-mediator variable distinction in social psychological research: Conceptual, strategic, and statistical considerations. Journal of Personality and Social Psychology, 51, 1173-1182.

Bredahl, L. (2001). Determinants of consumer attitudes and purchase intentions with regard to genetically modified foods: Results of a cross-national survey. Journal of Consumer Policy, 24, 23-61.

Burton, M., \& Pearse, D. (2003). Consumer attitudes towards genetic modification, functional foods, and microorganisms: A choice modeling experiment for beer. AgBioForum, 3, 14-19.

Frewer, L. J., Howard, C., \& Shepherd, R. (1996). The influence of realistic product exposure on attitudes towards genetic engineering of food. Food Quality and Preference, 7, 61-67.

Frewer, L. J., Howard, C., \& Shepherd, R. (1998). The influence of initial attitudes on responses to communication about genetic engineering in food production. Agriculture and Human Values, 15, 15-30.

Gamble, J., Muggleston, S., Hedderley, D., Parminter, T., \& Vaughan, G. (2000). Genetic engineering: The public's point of view. HortResearch NZ Client Report No. 2000/249. New Zealand: HortResearch NZ.

Grunert, K. G., Bredahl, L., \& Scholderer, J. (2003). Four questions on European consumers' attitudes toward the use of genetic modification in food production. Innovative Food Science and Emerging Technologies, 4, $435-445$.

Hossain, F., Onyango, B., Adelaja, A., Schilling, B., \& Hallman, W. (2002). Consumer acceptance of food biotechnology: Willingness to buy genetically modified food products. Food Policy Institute Report No. WP-0602-001. Rutgers University.

Judd, C. M., Kenny, D. A., \& McClelland, G. H. (2001). Estimating and testing mediation and moderation in within-subject designs. Psychological Methods, 6, 115-134.

MacKinnon, D. P., Lockwood, C. M., Hoffman, J. M., West, S. G., \& Sheets, V. (2002). A comparison of methods to test mediation and other intervening variable effects. Psychological methods, 7, 83-104.

MAPP annual report (2000). There is no accounting for tastes! Product advantages and tasting reduce consumers' scepticism towards genetically modified foods. Retrieved April 6, 2006, from http://crossenz.vtt.fi/mapp\%20annual\%20report\%202000consumerissues.pdf.

Onyango, B., \& Nayga, R. M., Jr. (2004). Consumer acceptance of nutritionally enhanced genetically modified food. Journal of Agricultural and Resource Economics, 29, 567-583.

Pew Initiative on Food and Biotechnology. (2003). Survey results: An update on public sentiment about agricultural biotechnology. Washingon, DC: The Mellman Group Inc.

Rozin, P., Spranca, M., Krieger, Z., Neuhaus, R., Surillo, D., Swerdlin, A., et al. (2004). Preference for natural: instrumental and ideational/moral motivations, and the contrast between foods and medicines. Appetite, 43, 147-154.

Saba, A., \& Vassallo, M. (2002). Consumer attitudes toward the use of gene technology in tomato production. Food Quality and Preference, 13, 13-21.

Tenbült, P., De Vries, N. K., Dreezens, E., \& Martijn, C. (2005). Perceived naturalness and acceptance of genetically modified food. Appetite, 45, 4750.

Tenbült, P., De Vries, N. K., Dreezens, E., \& Martijn, C. (2007). Categorizing genetically modified food products: Effects of labelling on information processing. British Food Journal, 109, 305-314.

Tenbült, P., De Vries, N. K., Dreezens, E., Martijn, C. (in press). Implicit and explicit attitudes toward organic and genetically modified food production: Attitude strength and familiarity. British Food Journal. 